\title{
Assessing adherence to the 2010 antiretroviral guidelines in the antiretroviral roll-out clinic at 1 Military Hospital, South Africa: A retrospective, cross-sectional study
}

\author{
A K Khwitshana, ${ }^{1}$ MB ChB, Dip HIV, MPharmMed; O B W Greeff, ${ }^{2}$ MB ChB, FCFP (SA), MPharmMed, FFPM (RCP), MD; \\ T Hurrell, ${ }^{2}$ MSc (Pharm) \\ ${ }^{1}$ Infectious Disease Clinic,1 Military Hospital, Pretoria, South Africa \\ ${ }^{2}$ Department of Pharmacology, School of Medicine, Faculty of Health Sciences, University of Pretoria, South Africa
}

Corresponding author: T Hurrell (tracey.hurrell@up.ac.za)

\begin{abstract}
Background. HIV research is a therapeutic area for which well-defined population-specific treatment and prophylaxis guidelines exist. However, there are limited objective, evidence-based data for assessing adherence to these guidelines.

Objective. To conduct a retrospective, cross-sectional study of adult HIV-infected patients receiving treatment at the antiretroviral (ARV) roll-out clinic of the Infectious Diseases Clinic Pharmacy at 1 Military Hospital (1MH) over a period of 3 years to assess clinicians' adherence to the 2010 ARV guidelines.

Methods. Pharmacy files from the pool of adult patients receiving treatment at the ARV roll-out clinic between 1 April 2009 and 31 March 2012 were selected. Variables used to establish adherence were assessed through evaluation of pharmacy scripts and laboratory tests.

Results. In accordance with the ARV guidelines, we found a switch in the first-line regimen from stavudine to tenofovir during the period following implementation. There was no difference in baseline blood tests conducted, suggesting that clinicians were recommending a standardised test panel. Notably, similar blood tests were routinely done during follow-up visits, despite no indication for doing so. While the number of blood tests was found to decrease over time, the type of blood tests requested for specific treatment regimens was not in accordance with the ARV guidelines.

Conclusion. We used an evidence-based approach to critically assess variations from the delineated ARV guidelines. Adherence to clinical guidelines at $1 \mathrm{MH}$, while demonstrating improvement in patient outcomes, highlighted the need for increased vigilance in monitoring failure of prescribers to comply with ARV guidelines.
\end{abstract}

S Afr Med J 2014;104(7):495-500. DOI:10.7196/SAMJ.7926

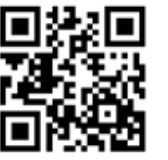

Advances in management and treatment of HIV/ AIDS have transformed HIV into a chronic condition rather than a debilitating terminal illness. Data on patient adherence suggest positive outcomes provided there is $>95 \%$ compliance with therapy. ${ }^{[1]}$

Well-defined, population-specific treatment and prophylaxis guidelines for treatment of HIV exist, ${ }^{[1]}$ which integrate scientific evidence and clinical expertise to produce clinically valid, operational recommendations with the aim of improving various health outcomes. These clinical practice guidelines can be defined as systematically developed statements for both practitioners and patients, to assist with appropriate healthcare decisions for specific clinical circumstances. ${ }^{[2]}$ Their intention is to improve healthcare processes, decrease practice variation and optimise use of resources to improve health outcomes.

However, studies reveal widespread variability among practitioners, notably in specialised domains with respect to adherence to the core recommendations of various practice guidelines. ${ }^{[3]}$

Antiretroviral treatment (ART), in the form of highly active antiretroviral therapy, consists of a combination of two nucleoside reverse transcriptase inhibitors (NRTIs) and a non-NRTI or a protease inhibitor. The South African (SA) 2004 antiretroviral (ARV) guidelines recommended a combination of stavudine $(\mathrm{d} 4 \mathrm{~T})$ and lamivudine (3TC) as the NRTI backbone in the first-line regimen and a combination of zidovudine (AZT) and didanosine (DDI) as the backbone in the second-line regimen. ${ }^{[4]}$ Unfortunately, both $\mathrm{d} 4 \mathrm{~T}$ and DDI were found to be major culprits in the onset of metabolic toxicities and became further implicated in development of fatal complications such as lactic acidosis. ${ }^{[5,6]}$

Currently SA has the largest HIV treatment programme in the world, with $\sim 1.3$ million people receiving ART by the end of $2010{ }^{[7]}$ However, burdensome adverse effects, although varying in their impact, have concerned government, healthcare providers and patients alike. As a result, the 2010 ARV guidelines focused on curbing morbidity and mortality associated with $\mathrm{d} 4 \mathrm{~T}$ and DDI. These and subsequent guidelines suggested replacing $\mathrm{d} 4 \mathrm{~T}$ and DDI with less toxic alternatives such as tenofovir (TDF) as the first-line regimen and $3 \mathrm{TC}$ as the second-line regimen.

The 2010 ARV treatment guidelines advised:

- when to initiate therapy

- what drugs to use in the first-line regimen

- when to modify therapy

- what combinations of drugs to use when a change was indicated

- what laboratory tests to do prior to treatment initiation

- how often to monitor treatment

- what laboratory tests to repeat during follow up visits. ${ }^{[8]}$

Ordinarily, subjective approaches such as interviews and self-report questionnaires by clinicians themselves are used to determine adherence to guidelines and success of therapeutic endeavours. There are limited published data, both locally and internationally, for assessing adherence to these guidelines using objective evidence- 
based approaches such as assessing prescriptions and the choice of laboratory tests associated with specific drug regimens, as delineated in the guidelines.

The aim of this study was to assess compliance with the 2010 ARV guidelines to determine the degree of guideline implementation and provide insight into changes required to strengthen subsequent guideline implementation.

\section{Methods Ethical approval}

Ethical clearance to review patient records was obtained from the Faculty of Health Sciences Research Ethics Committee of the University of Pretoria (reference no. 27/2013) and 1 Military Hospital (1MH) Ethics Committee (reference no. 1MH/302/6). Patient confidentiality was strictly maintained with no identifying file numbers being presented on datasheets, compiled results or manuscripts.

\section{Study design}

A retrospective, cross-sectional study of adult HIV-infected patients receiving treatment prescriptions and management at the ARV roll-out clinic of the Infectious Diseases Clinic Pharmacy at $1 \mathrm{MH}$ over a period of 3 years, to assess clinicians' adherence to the 2010 ARV guidelines through the evaluation of pharmacy scripts and laboratory tests ordered.

\section{Data collection}

Approximately 300 pharmacy files from the pool of adult patients receiving ART between 1 April 2009 and 31 March 2012 were selected using a predetermined randomisation system. From the 300 randomised adult patient files selected, 252 met the inclusion criteria ( $>18$ years of age and continuing to receive ART).

The files were subsequently divided into three patient categories:

- Group 1: adult patients who were dispensed ART between 1 April 2009 and 31 March 2010 (1 year prior to implementation of the 2010 ART guideline) ( $n=77)$.

- Group 2: adult patients who received ART between 1 April 2010 and 31 March 2011 (year 1 of implementation of the 2010 ART guideline) ( $n=83)$

- Group 3: adult patients who were dispensed ART between 1 April 2011 and 31 March 2012 (2 years after implementation of the 2010 ART guideline) $(n=92)$.

Patient files were audited for demographic characteristics; drugs dispensed in both first- and second-line regimens; $\mathrm{CD}^{+}$ counts for patient cohorts initiating
Table 1. Sample demographics

\begin{tabular}{llll}
\hline & Group 1 & Group 2 & Group 3 \\
\hline $\begin{array}{l}\text { Sample size, } n \\
\text { Gender, } n \text { (\%) }\end{array}$ & 77 & 83 & 92 \\
$\quad$ Female & $28(36.36)$ & $26(31.33)$ & $35(38.04)$ \\
$\quad$ Male & $49(63.64)$ & $57(68.67)$ & $57(61.06)$ \\
Age (years) & & & \\
$\quad$ Mean (SD) & $42.49(5.49)$ & $41.75(4.89)$ & $42.07(7.30)$ \\
$\quad$ Median & 41 & 41 & 42 \\
$\quad$ Lower quartile & 39 & 39 & 38 \\
$\quad$ Upper quartile & 46 & 45 & 45 \\
SD = standard deviation. & & &
\end{tabular}

Table 2. Prescriptions per month for drugs in each group before and after the new guidelines (mean $n$ )

\begin{tabular}{llllll}
\hline Drug & $\begin{array}{l}\text { Group 1, } \\
\text { pre-2010 }\end{array}$ & $\begin{array}{l}\text { Group 1, } \\
\text { post-2010 }\end{array}$ & $\begin{array}{l}\text { Group 2, } \\
\text { post-2010 }\end{array}$ & $\begin{array}{l}\text { Group 3, } \\
\text { post-2010 }\end{array}$ & $\begin{array}{l}\text { Post-2010, } \\
\text { combined mean }\end{array}$ \\
\hline Abacavir & 1.00 & 0.92 & 0.00 & 3.08 & 1.33 \\
Aluvia & 6.00 & 11.04 & 16.29 & 10.00 & 12.44 \\
Combivir & 2.17 & 2.63 & 0.46 & 0.17 & 1.09 \\
DDI & 1.42 & 2.63 & 2.42 & 0.00 & 1.68 \\
EFV & 57.67 & 60.79 & 61.88 & 64.25 & 62.31 \\
3TC & 61.17 & 63.38 & 68.58 & 64.42 & 65.46 \\
NVP & 3.50 & 2.67 & 0.78 & 0.92 & 1.46 \\
Reyataz & 0.00 & 0.75 & 1.46 & 1.00 & 1.07 \\
D4T & 49.50 & 35.42 & 32.96 & 17.00 & 28.46 \\
TDF & 4.17 & 20.75 & 30.21 & 38.83 & 29.93 \\
Truvada & 2.50 & 6.46 & 8.00 & 13.17 & 9.21 \\
AZT & 7.92 & 8.71 & 8.50 & 6.00 & 7.74 \\
DDI = didanosine; EFV & $=$ efavirenz; $3 \mathrm{TC}=$ lamivudine; NVP = nevirapine; D4T = stavudine; TDF = tenofovir; \\
AZT = zidovudine. & & & & & \\
& & & & &
\end{tabular}

Table 3. Monthly prescriptions for each group pre- and post-2010 (differences in means)

\begin{tabular}{|c|c|c|c|c|c|}
\hline Drug & $\begin{array}{l}\text { Group 1, } \\
\text { pre-2010 }\end{array}$ & $\begin{array}{l}\text { Group 1, } \\
\text { post-2010 }\end{array}$ & $\begin{array}{l}\text { Group 2, } \\
\text { post-2010 }\end{array}$ & $\begin{array}{l}\text { Group 3, } \\
\text { post-2010 }\end{array}$ & $\begin{array}{l}\text { Post-2010, } \\
\text { mean } \\
\text { difference }\end{array}$ \\
\hline Abacavir & 1.00 & -0.08 & -1.00 & 2.08 & 0.33 \\
\hline Aluvia & 6.00 & 5.04 & 10.29 & 4.00 & 6.44 \\
\hline Combivir & 2.17 & 0.46 & -1.71 & -2.00 & -1.08 \\
\hline DDI & 1.42 & 1.21 & 1.00 & -1.42 & 0.26 \\
\hline EFV & 57.67 & 3.12 & 4.21 & 6.58 & 4.64 \\
\hline $3 \mathrm{TC}$ & 61.17 & 2.21 & 7.41 & 3.25 & 4.29 \\
\hline NVP & 3.50 & -0.83 & -2.72 & -2.58 & -2.04 \\
\hline Reyataz & 0.00 & 0.75 & 1.46 & 1.00 & 1.07 \\
\hline $\mathrm{D} 4 \mathrm{~T}$ & 49.50 & -14.08 & -16.54 & -32.5 & -21.04 \\
\hline TDF & 4.17 & 16.58 & 26.04 & 34.66 & 25.76 \\
\hline Truvada & 2.50 & 3.96 & 5.50 & 10.67 & 6.71 \\
\hline $\mathrm{AZT}$ & 7.92 & 0.79 & 0.58 & -1.92 & -0.18 \\
\hline
\end{tabular}


treatment at $\leq 350$ cells $/ \mu \mathrm{l}$ v. $\leq 200 \mathrm{cells} / \mu \mathrm{l}$; frequency and timing of blood tests after initiation of ART; number of drug substitutions (including the reason for and timing of substitution); evidence of comorbidity based on pharmacy records for any antituberculosis treatment issued; and the time (months) to drug substitution to comply with the new treatment guidelines.

\section{Laboratory tests}

Data regarding laboratory tests were extracted from the hospital computer system. All laboratory tests requested by doctors during patient visits at baseline and during subsequent monitoring visits were done by $1 \mathrm{MH}$. Laboratory tests routinely requested included full blood count (FBC); urea and electrolytes (U\&E); liver function tests (LFTs) (total protein, albumin, total bilirubin, alanine aminotransferase (ALT), aspartate aminotransferase, alkaline phosphatase and $\gamma$-glutamyl transpeptidase), hepatitis B serology; $\mathrm{CD} 4^{+}$count and HIV viral load (VL).

Laboratory tests, each highly drug specific, were assessed to determine whether the correct suggested blood tests, and timing of their monitoring, were done as recommended by the 2010 guidelines. For example, FBC is recommended at 1, 2, 3 and 6 months if the patient is receiving AZT; creatinine needs be monitored at months 3 and 6 , and thereafter annually, if the patient is receiving TDF; and fasting cholesterol and triglycerides monitored at month 3 if the patient is receiving Aluvia (lopinavir/ritonavir; Abbott Laboratories), and then annually thereafter. ${ }^{[9]}$

Table 4. Blood tests done at monitoring visits for each group per regimen (mean $n$ )

\begin{tabular}{|c|c|c|c|c|c|c|}
\hline Regimen & FBC & $\mathrm{U} \& \mathrm{E}$ & LFTs & CD4 & VL & HEP \\
\hline \multicolumn{7}{|c|}{ Group 1 (before April 2010) } \\
\hline \multicolumn{7}{|l|}{ New regimen } \\
\hline $\mathrm{D} 4 \mathrm{~T}$ & 2.81 & 2.75 & 2.75 & 2.81 & 1.50 & 0.56 \\
\hline \multicolumn{7}{|l|}{ Old regimen } \\
\hline $\mathrm{D} 4 \mathrm{~T}$ & 3.22 & 3.24 & 3.24 & 3.20 & 2.82 & - \\
\hline TDF & 4.00 & 4.00 & 4.00 & 4.00 & 3.00 & - \\
\hline AZT/NVP & 3.50 & 3.50 & 3.50 & 3.50 & 2.00 & - \\
\hline \multicolumn{7}{|l|}{ Group 1 (after April 2010) } \\
\hline \multicolumn{7}{|l|}{ New regimen } \\
\hline $\mathrm{D} 4 \mathrm{~T}$ & 5.56 & 5.56 & 5.56 & 5.63 & 5.13 & - \\
\hline \multicolumn{7}{|l|}{ Old regimen } \\
\hline $\mathrm{D} 4 \mathrm{~T}$ & 5.49 & 5.51 & 5.47 & 5.49 & 4.92 & - \\
\hline TDF & 5.00 & 5.00 & 5.00 & 5.00 & 4.50 & - \\
\hline $\mathrm{AZT} / \mathrm{EFV}$ & 6.25 & 6.25 & 6.25 & 6.25 & 5.75 & \\
\hline AZT/NVP & 4.50 & 4.50 & 4.50 & 4.50 & 4.50 & - \\
\hline \multicolumn{7}{|c|}{ Group 2 (year 1 of 2010 guideline adoption) } \\
\hline \multicolumn{7}{|l|}{ New regimen } \\
\hline $\mathrm{D} 4 \mathrm{~T}$ & 5.92 & 5.92 & 5.85 & 5.92 & 4.85 & 0.23 \\
\hline TDF & 5.89 & 5.89 & 5.89 & 5.89 & 4.44 & 0.22 \\
\hline \multicolumn{7}{|l|}{ Old regimen } \\
\hline TDF & 5.76 & 5.76 & 5.71 & 5.76 & 5.48 & \\
\hline $\mathrm{AZT} / \mathrm{EFV}$ & 5.56 & 5.56 & 5.44 & 5.56 & 4.56 & - \\
\hline $\mathrm{AZT} / \mathrm{EFV}$ & 5.75 & 5.75 & 5.50 & 5.75 & 4.75 & - \\
\hline AZT/Videx/Aluvia & 4.00 & 4.00 & 4.00 & 4.00 & 4.00 & - \\
\hline \multicolumn{7}{|c|}{ Group 3 (year 2 of 2010 guideline adoption) } \\
\hline \multicolumn{7}{|l|}{ New regimen } \\
\hline $\mathrm{D} 4 \mathrm{~T}$ & 2.00 & 2.00 & 1.00 & 2.00 & 0.00 & 1.00 \\
\hline TDF & 2.38 & 2.38 & 2.28 & 2.28 & 1.88 & 0.24 \\
\hline \multicolumn{7}{|l|}{ Old regimen } \\
\hline Abacavir & 3.00 & 3.00 & 3.00 & 3.00 & 2.50 & - \\
\hline NVP & 3.00 & 3.00 & 3.00 & 3.00 & 3.00 & - \\
\hline $\mathrm{D} 4 \mathrm{~T} / \mathrm{EFV}$ & 2.82 & 2.82 & 2.73 & 2.82 & 2.27 & - \\
\hline TDF/EFV & 2.60 & 2.60 & 2.60 & 2.60 & 2.30 & - \\
\hline AZT/Aluvia & 2.00 & 2.00 & 2.00 & 2.00 & 2.00 & - \\
\hline
\end{tabular}




\section{Statistical analysis}

Descriptive statistics for categorical data were summarised and tabulated while mean and/or median values were calculated for continuous variables such as age. Analysis of variance was used to compare drugs in the first- and second-line regimens during the analysis period (between the two periods and among the groups, respectively, where required). Fisher's exact test was used to compare mean values for blood tests, time intervals and $\mathrm{CD} 4^{+}$count outcome variables during the analysis period (between the two periods and among the groups, respectively, where required). Statistical analysis was done using SAS 9.2 statistical software, with $p$-values of $<0.05$ considered statistically significant.

\section{Results}

Demographic characteristics are summarised in Table 1. Of note, the number of men receiving treatment was higher in all three groups.

When assessing the predominant drugs used over the duration of this study (Tables 2 and 3), it was noted that the mean number of $\mathrm{d} 4 \mathrm{~T}$ prescriptions used in first-line regimens declined significantly in all groups $(p<0.001)$. There was a resultant decrease of 21 scripts when comparing pre-2010 data with an average of the three groups, post-implementation of the 2010 ARV guidelines. Use of TDF was limited prior to introduction of the 2010 guideline, with a subsequent statistically significant $(p<0.001)$ increase within the years following implementation of the 2010 guidelines. This resulted in an increase of 25 scripts when comparing pre-2010 data with an average of the three groups post-implementation.

These data also describe the decline in DDI use $(p<0.001)$, which was no longer recommended. While there was no significant difference $(p<0.145)$ in 3TC across the groups, owing to its use in both first and second line regimens, there was a trend suggesting a preference for the fixed-dose combination of Truvada (emtricitabine and TDF; Gilead Sciences, USA) over TDF with 3TC in the later stages of the study.

According to the $2010 \mathrm{ARV}$ guidelines, the $\mathrm{CD} 4^{+}$criterion for initiation was $\leq 200$ cells/ $\mu$, with the exception of special cohorts of patients presenting with pregnancy or tuberculosis (TB), who were initiated on therapy with $\mathrm{CD}^{+}$counts $<350$ cells $/ \mu$ l. The number of patients with $\mathrm{CD}^{+}$counts $\leq 200$ cells/ $\mu$ l or 200 350 cells $/ \mu$ l, both pre-and post-April 2010, including the special cohorts, was therefore compared. This yielded no significant differences in the non-specialised population $(p=1.00)$, pregnant women ( $p$-value not applicable owing to small sample size), or patients with TB ( $p=0.233$ and 0.466 , respectively, before and after guideline implementation).

Baseline tests conducted regularly included FBC, U\&E, LFTs, CD4 ${ }^{+}$ count, VL and, in a minority population where warranted, hepatitis B serology. Comparing baseline blood tests conducted pre- and postimplementation using a $\chi^{2}$ test, there was no statistically significant difference. This suggested that clinicians were recommending a standard panel of tests to which they had become accustomed.

The number of blood tests done for newly initiated patients, and for those already receiving treatment, was the same at baseline regardless of the drug regimen (Table 4). The same blood tests done at initiation were routinely done during follow-up, despite there being no guideline indication for doing so. However, omission of LFTs and hepatitis B serology was adhered to, as recommended in the ARV guidelines.

Assessment of the time interval in months for follow-up monitoring visits revealed that the choice of blood tests was similar across all regimens. Only in group 3, and 2 years post-implementation of the 2010 guidelines, was a slightly more drug-dependent approach
Table 5. Time interval for monitoring blood test for each respective regimen

\begin{tabular}{ll}
\hline Regimen & $\begin{array}{l}\text { Time interval } \\
\text { (months), mean }\end{array}$ \\
\hline Group 1 (before April 2010) & \\
New regimen & \\
D4T & 3.67 \\
Old regimen & \\
D4T & 3.31 \\
TDF & 2.57 \\
AZT & 3.25
\end{tabular}

Group 1 (after April 2010)

New regimen

TDF

Old regimen

D4T

TDF

4.50

AZT

Group 2 (year 1 of 2010 guideline adoption)

New regimen

D4T

3.85

TDF

3.68

Old regimen

D4T 3.96

TDF 4.55

AZT/Aluvia $\quad 5.75$

AZT/EFV 3.86

Group 3 (year 2 of 2010 guideline adoption)

New regimen

D4T 4.00

TDF 2.50

Old regimen

NVP $\quad 3.50$

D4T 4.26

TDF $\quad 3.50$

Truvada $\quad 3.60$

AZT/EFV 4.13

$\mathrm{D} 4 \mathrm{~T}$ = stavudine; $\mathrm{TDF}=$ tenofovir; $\mathrm{AZT}=$ zidovudine; $\mathrm{NVP}=$ nevirapine.

observed regarding prescription of TDF and $\mathrm{d} 4 \mathrm{~T}$ and timing of blood tests (Table 5).

The most prevalent side-effects (Table 6) that resulted in drug substitution included hepatotoxicity, peripheral neuropathy and lipodystrophies and lipoatrophies, most often associated with $\mathrm{d} 4 \mathrm{~T}$. Additional reasons for $\mathrm{d} 4 \mathrm{~T}$ substitution included virological failure, which was higher in groups 1 and 2 and involved 12 and eight patients, respectively, compared with only three patients in group 3 (which was probably associated with the decreased use of $\mathrm{d} 4 \mathrm{~T}$ to comply with the 2010 guidelines).

Additionally, ten, 11 and two patients in groups 1,2 and 3, respectively, substituted $\mathrm{d} 4 \mathrm{~T}$ with TDF or Truvada to comply with the 2010 guidelines. 
Table 6. Side-effects as reasons for drug substitution in all three groups

\begin{tabular}{|c|c|c|c|c|c|c|}
\hline Side-effect & Aluvia, $n$ & AZT, $n$ & D4T, $n$ & $\mathrm{EFV}, n$ & TDF, $n$ & Total, $N$ \\
\hline \multicolumn{7}{|l|}{ Group 1} \\
\hline Anaemia & - & 1 & - & - & - & 1 \\
\hline Diarrhoea & 2 & - & - & - & - & 2 \\
\hline Dizziness or confusion & - & - & - & 1 & - & 1 \\
\hline Hepatoxicity & - & 3 & 4 & - & - & 7 \\
\hline Lipodystrophies and atrophies & - & 3 & 18 & - & - & 21 \\
\hline Peripheral neuropathy & - & - & 11 & - & - & 11 \\
\hline Renal dysfunction & - & - & - & - & 2 & 2 \\
\hline Unexplained weight loss & - & - & 4 & - & - & 4 \\
\hline Total, $N$ & 2 & 7 & 37 & 1 & 2 & 47 \\
\hline \multicolumn{7}{|l|}{ Group 2} \\
\hline Anaemia & - & - & - & - & - & 0 \\
\hline Diarrhoea & 2 & - & - & - & - & 2 \\
\hline Dizziness or confusion & - & - & - & 2 & - & 2 \\
\hline Hepatitis & - & - & 1 & - & - & 1 \\
\hline Lipodystrophies and atrophies & - & - & 9 & - & - & 9 \\
\hline Peripheral neuropathy & - & - & 12 & - & - & 12 \\
\hline Renal dysfunction & - & - & - & - & 1 & 1 \\
\hline Unexplained weight loss & - & - & 1 & - & - & 1 \\
\hline Total, $N$ & 2 & - & 23 & 2 & 1 & 28 \\
\hline \multicolumn{7}{|l|}{ Group 3} \\
\hline Hepatoxicity & - & - & 2 & - & - & 2 \\
\hline Lipodystrophies and atrophies & - & - & 6 & - & - & 6 \\
\hline Peripheral neuropathy & - & - & 0 & - & - & 0 \\
\hline Psychosis & - & - & - & 1 & - & 1 \\
\hline Renal dysfunction & - & - & - & - & 5 & 5 \\
\hline Unexplained weight loss & - & - & - & - & - & 0 \\
\hline Total, $N$ & - & - & 8 & 1 & 5 & 14 \\
\hline
\end{tabular}

Survival analysis indicated that patients in group 3 required changes in treatment due to treatment failure at a much later stage than patients in groups 1 and 2 .

Time taken in months to comply with the new guidelines of 1 April 2010 was measured by determining the time required for $\mathrm{d} 4 \mathrm{~T}$ to be replaced by TDF in the first-line regimen, and DDI by $3 \mathrm{TC}$ in the second-line regimen. In the first-line regimen, only patients who substituted drugs on the basis of complying with the new guidelines were considered, substitutions due to side-effects being excluded. The decrease in $\mathrm{d} 4 \mathrm{~T}$ and increase in TDF scripts for first-line regimens occurred in groups 2 and 3 , at least 1 year post-implementation.

In the second-line regimen, substitution to $3 \mathrm{TC}$ followed development of virological failures as recommended in new guidelines made available during the study. From the time of introduction of the new guidelines, which was considered baseline, an average of 2.42 scripts for DDI were given in group 2, which was already a year after implementation of the new guidelines. However, in compliance with the guidelines, zero scripts for DDI were dispensed for group 3 (2011 - 2012), with, however, a delay of over a year for DDI prescriptions to cease completely.

\section{Discussion}

In the year prior to implementation of the 2010 guidelines, $\mathrm{d} 4 \mathrm{~T}$ prescriptions were high, with 590 prescriptions dispensed v. only 50 for TDF in the same time period. This paradigm began to shift within the first year of the new ARV guidelines. A striking rise in the choice of Truvada over the single TDF and 3TC was observed, which may be expected to increase in the years to come.

According to the 2010 guidelines, the recommended blood tests at baseline include $\mathrm{CD}^{+}$count, haemoglobin $(\mathrm{Hb})$ or FBC if starting on AZT, serum creatinine if TDF is considered, and ALT if nevirapine (NVP) is initiated. The 2010 guidelines suggested that VL and $\mathrm{CD} 4^{+}$count be done only during monitoring of treatment at 6 months, then at 12 months, and thereafter at annual intervals. ${ }^{[8]}$ Hepatitis screening was not included in the 2010 guidelines; however, the 2013 guidelines included hepatitis screening at baseline, with ALT required only if the patient was prescribed NVP and developed rash or symptoms of hepatitis..$^{[9]}$

On average, tests for monitoring were conducted more frequently than indicated in the guidelines. Baseline tests ordered at the clinic were excessive, and did not take into account the choice of initial drug/s prescribed. 
There was no difference in the number or types, of blood tests ordered for the d4T-based regimens before and after implementation of the 2010 guidelines. While timing intervals of blood tests for AZT-based regimens more closely complied with guidelines in the last year of the study, there was no evidence of $\mathrm{Hb}$ or FBC measured monthly for the first 3 months for patients newly initiated on AZT, as per recommendation.

The d4T-based regimen had 619 blood tests for each of FBC and LFTs, not all of which were indicated; however, ALT was warranted if the regimen included NVP and symptoms of hepatitis became evident. There were 225 unjustified FBCs and LFTs in patients receiving the TDF-based regimen over the same period. It was also noted that an average of three blood tests were routinely done for abacavir, which has no known side-effects warranting blood test monitoring. These unnecessary tests incurred significant costs.

Patients in all three groups on Aluvia-based regimens had no blood tests done for fasting cholesterol and triglycerides to monitor the side-effects of these drugs, despite their recommendation in the new guidelines. This potentially places patients at risk of developing dyslipidaemias, and cardiovascular events, which are strongly associated with this drug.

The 2010 guidelines clearly stated that ART be initiated at a CD4 ${ }^{+}$ count $\leq 200$ cells $/ \mu$ with the exception of pregnancy and TB, where the $\mathrm{CD} 4^{+}$count for starting treatment is $350 \mathrm{cells} / \mu \mathrm{l} .^{[8]}$ (Within the 2013 guidelines, SA has fully implemented the new $\mathrm{CD}^{+}$count criteria where the level of $\mathrm{CD}^{+}$count for initiation is $\leq 350$ copies $/ \mu$, and at any $\mathrm{CD} 4^{+}$count where $\mathrm{TB}$ or pregnancy is present.)

It was not surprising to see that there were no pregnant women with a CD4 count $<200$ copies/ $\mu$ l, because at $1 \mathrm{MH}$ all HIV-positive pregnant women are placed on ARV treatment regardless of $\mathrm{CD}_{4}^{+}$ count as part of the prevention of mother-to-child transmission programme. Following delivery, those eligible for ARV treatment continue while treatment is discontinued in those not eligible. TB patients continue to present very late in their disease course, when the $\mathrm{CD} 4^{+}$count is already very low; hence only 10 patients had $\mathrm{CD} 4{ }^{+}$counts of $200-350$ copies/ $\mu$ at initiation v. 23 patients with $<200$ copies/ $\mu$ l.

TDF was already being dispensed at $1 \mathrm{MH}$ by the time the new 2010 guidelines were implemented, but was reserved for patients experiencing side-effects of $\mathrm{d} 4 \mathrm{~T}$. However, implementation was associated with an impressive decline in side-effects, implying that the rising use of TDF was yielding positive patient outcomes with potentially lower numbers of patients experiencing treatment failure.

\section{Study limitation}

This study was conducted at only one site.

\section{Conclusion}

The lifespan of HIV patients receiving ARV treatment is improving, but risk factors associated with long-term drug treatment are increasing. This is one of the first studies in SA to use objective evidence-based approaches to critically assess variance from ARV guidelines to determine compliance on the part of prescribing clinicians.

We found that compliance to ARV guidelines at the roll-out clinic at $1 \mathrm{MH}$ was satisfactory in some areas and not in others. Improvement in patient outcomes was demonstrated by a declining number of side-effects, most notably in the first-line regimen where TDF demonstrated a greater tolerability than $\mathrm{d} 4 \mathrm{~T}$. However, an increased need for vigilance is required with regard to blood test monitoring, where clinicians fail to comply with the ARV guidelines. Addressing these issues may significantly alleviate the financial burden faced by healthcare organisations.

Acknowledgements. We thank Prof. D G van Zyl of Kalafong Hospital for his contributions to the methodology, as well as Dr T Rossouw from the University of Pretoria who assisted with the study design, Mr L Sibitsiwa of $1 \mathrm{MH}$ who aided in data capturing, and Prof. L Schoemanof and Mr L O Kondlo who assisted in the statistical analysis.

\section{References}

1. Machtinger EL, Bangsberg DR. Adherence to HIV Antiretroviral Therapy. HIV InSite Knowledge Base Chapter. San Francisco, USA: HIV InSite, 2005. http://hivinsite.ucsf.edu/InSite?page=kb-03-02-09\# (accessed 24 March 2014)

2. Dykes PC. Practice guidelines and measurement: State-of-the-science. Nurs Outlook 2003;51(2):6569. [http://dx.doi.org/10.1016/s0029-6554(02)05459-3]

3. Spallek H, Song M, Plok DE, Bekhuis T, Frantsve-Hawley J, Aravamudhan K. Barriers to implementing evidence based-clinical guidelines: A survey of early adopters. Evid Based Dent Pract 2010;10(4):195206. [http://dx.doi.org/10.1016/j.jebdp.2010.05.013]

4. National Department of Health. National Antiretroviral Treatment Guidelines. 1st ed. Pretoria: Jacana, 2004. http://southafrica.usembassy.gov/media/2004-doh-art-guidelines.pdf (accessed 24 March 2014). Boulle A, Orrell C, Kaplan R, et al Substitutions due to antiretroviral toxicity or contra-indications in the first 3 years of antiretroviral therapy in a large South African cohort. Antivir Ther 2007;12(5):753-760.

6. Bolhaar MG, Karstaedt AS. A high incidence of lactic acidosis and symptomatic hyperlactatemia in women receiving highly active antiretroviral therapy in Soweto, South Africa. Clin Infect Dis in women receiving highly active antiretroviral therapy

7. WHO, UNICEF, UNAIDS. Global Update on HIV Treatment 2013. Geneva: WHO, 2013. http://www who.int/iris/bitstream/10665/85327/1/WHO_HIV_2013.9_eng.pdf (accessed 24 March 2014).

8. National Department of Health. The South African Antiretroviral Treatment Guidelines 2010 Pretoria: NDoH, 2010. http://www.uj.ac.za/EN/CorporateServices/ioha/Documentation/Documents/ ART\%20Guideline.pdf (accessed 24 March 2014).

9. National Department of Health. The South African Antiretroviral Treatment Guidelines 2013. Pretoria: NDoH, 2013. http://www.auruminstitute.org/phocadownload/guidelines-short.pdf (accessed 24 March 2014)

Accepted 24 February 2014 